\title{
Slow Ventricular Conduction in Mice Heterozygous for a Connexin43 Null Mutation
}

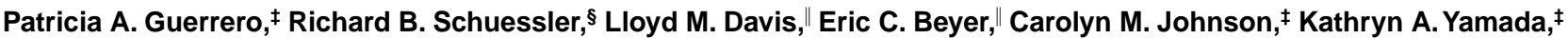 \\ and Jeffrey E. Saffitz ${ }^{\star \ddagger}$ \\ $*$ Department of Pathology, ${ }^{\ddagger}$ Department of Medicine, ${ }^{\S}$ Department of Surgery, and ${ }^{\|}$Department of Pediatrics, Washington University, \\ St. Louis, Missouri 63110
}

\begin{abstract}
To characterize the role of the gap junction protein connexin43 (Cx43) in ventricular conduction, we studied hearts of mice with targeted deletion of the $\mathrm{Cx} 43$ gene. Mice homozygous for the $\mathrm{Cx} 43$ null mutation (Cx43 -/-) die shortly after birth. Attempts to record electrical activity in neonatal $\mathrm{Cx} 43$ $-I-$ hearts $(n=5)$ were unsuccessful. Ventricular epicardial conduction of paced beats, however, was $30 \%$ slower in heterozygous $(\mathrm{Cx} 43-I+)$ neonatal hearts $(0.14 \pm 0.04 \mathrm{~m} / \mathrm{s}$, $n=27)$ than in wild-type $(\mathrm{Cx} 43+/+)$ hearts $(0.20 \pm 0.07 \mathrm{~m} / \mathrm{s}$, $n=32 ; P<0.001)$. This phenotype was even more severe in adult mice; ventricular epicardial conduction was $44 \%$ slower in 6-9 mo-old Cx43 $-/+$ hearts $(0.18 \pm 0.03 \mathrm{~m} / \mathrm{s}, n=5)$ than in wild-type hearts $(0.32 \pm 0.07 \mathrm{~m} / \mathrm{s}, n=7, P<0.001)$. Electrocardiograms revealed significant prolongation of the QRS complex in adult Cx43-I+ mice (13.4 $\pm 1.8 \mathrm{~ms}, n=13)$ compared with $\mathrm{Cx} 43+I+$ mice $(11.5 \pm 1.4 \mathrm{~ms}, n=12, P<$ $0.01)$. Whole-cell recordings of action potential parameters in cultured disaggregated neonatal ventricular myocytes from $\mathrm{Cx} 43-I+$ and $+I+$ hearts showed no differences. Thus, reduction in the abundance of a major cardiac gap junction protein through targeted deletion of a $\mathrm{Cx} 43$ allele directly leads to slowed ventricular conduction. (J. Clin. Invest. 99:1991-1998.) Key words: cardiac connexins - gap junctions - impulse propagation - targeted gene deletion • electrophysiology
\end{abstract}

\section{Introduction}

The conduction properties of different cardiac tissues (such as atrial and ventricular muscle and the nodes and bundles of the conduction system) vary considerably (1). These differences can be explained in part by variations in ionic currents involved in depolarization and repolarization. The electrical network made up by the discrete spatial distribution of cytoplasmic and junctional resistances to current flow, however, also appears to be of fundamental importance (2). These passive electrical properties are determined mainly by the size and shape of the cardiac myocytes, the configuration and composition of the extracellular space, and the three-dimensional dis-

Address correspondence to Jeffrey E. Saffitz, M.D. Ph.D., Department of Pathology, Box 8118, Washington University School of Medicine, 660 S. Euclid Avenue, St. Louis, MO 63110. Phone: 314-3627728; FAX: 314-362-4096; E-mail: saffitz@pathology.wustl.edu

Received for publication 1 November 1996 and accepted in revised form 5 February 1997.

J. Clin. Invest.

(C) The American Society for Clinical Investigation, Inc.

0021-9738/97/04/1991/08 \$2.00

Volume 99, Number 8, April 1997, 1991-1998 tribution of discrete sites of electrical coupling at gap junctions.

Like most differentiated cells, individual cardiac myocytes express multiple connexins (3-5), members of a family of proteins that form gap junction channels (6). Different cardiac tissues that exhibit distinct conduction properties express different combinations of three cardiac connexins: connexin43 (Cx43), connexin45 (Cx45), and connexin40 (Cx40) $(4,5)$. In expression systems, these individual proteins form channels that differ in their unitary conductances and other biophysical properties (7). In addition, the number and three-dimensional distribution of intercellular connections at gap junctions differ markedly among different cardiac tissues in patterns that are consistent with the distinct anisotropic conduction properties of each tissue $(1,5,7)$. Thus, tissue-specific connexin phenotypes and gap junction distributions appear to be major determinants of the disparate conduction properties of cardiac tissues. Although this hypothesis is supported by a large body of indirect evidence, there has been no direct analysis of the functional roles of individual connexins in myocardial impulse propagation.

Because myocardial conduction is determined by many interdependent active and passive factors, it has been difficult to elucidate the contributions of single proteins or channels under experimental conditions that do not also change other determinants of conduction. The advent of techniques to manipulate genetic expression in mice provides an experimental approach to identify the role of specific gene products within the highly complex milieu of the heart. Toward this end, we have studied the $\mathrm{Cx} 43$ knockout mouse produced by Reaume et al. (8) to delineate the functional role of $\mathrm{Cx} 43$, the predominant cardiac connexin, in ventricular conduction. Mice homozygous for the $\mathrm{Cx} 43$ null mutation exhibit a malformation of the conus, causing right ventricular outflow tract obstruction and death shortly after birth. Therefore, $\mathrm{Cx} 43-/-$ mice must be studied as neonates. We have discovered, however, that hearts from neonatal and adult heterozygous animals, which survive and breed without apparent abnormality, exhibit slow ventricular conduction. These data provide direct evidence of the importance of connexin abundance as a determinant of cardiac conduction properties.

\section{Methods}

Cx43 mutant mice. Preliminary studies were performed on hearts from neonatal mice homozygous for $\mathrm{Cx} 43$ null mutations ( $\mathrm{Cx} 43-/-)$, heterozygous for $\mathrm{Cx} 43$ null mutations $(\mathrm{Cx} 43-/+)$ or wild-type litter mates $(\mathrm{Cx} 43+/+)$ that were generously provided to us by Dr. Janet Rossant of the University of Toronto. The majority of studies were performed on neonatal and adult animals produced in our mouse colony using breeders purchased from the Jackson Laboratories (Bar Harbor, ME). Mice were housed in barrier facilities under standard conditions. All pregnancies were timed by housing breeding pairs together for $24 \mathrm{~h}$. All mice were maintained in an inbred background 
(C57BL/6) so that effects due to genetic variation were minimized. The genotypes of all mice were determined by PCR, using primer sequences and protocols identical to those described by Reaume et al. (8) in their original report of the $\mathrm{Cx} 43-/-$ mouse.

Conduction studies. Conduction velocity was measured on the ventricular epicardial surface in superfused neonatal hearts and perfused adult hearts. Hearts of neonatal and adult mice were rapidly excised and placed in oxygenated cardioplegic solution (Plegisol; Abbott Labs, Chicago, IL) at $4^{\circ} \mathrm{C}$. The time in cardioplegic solution varied from 5-222 min for neonatal hearts. There was no correlation between the amount of time in cold cardioplegic solution and subsequent measurements of heart rate or conduction velocity. Because Cx43 $-/+$ and $+/+$ mice were indistinguishable, electrophysiologic measurements were performed without prior knowledge of genotype. Conduction in neonatal hearts was measured in a 7-ml tissue bath with continuous superfusion of oxygenated Krebs-Henseleit buffer at $31^{\circ} \mathrm{C}$ at a flow rate of $12 \mathrm{ml} / \mathrm{min}$. Adult hearts were perfused with the same buffer via an aortic cannula at a flow rate of $1.0-1.2 \mathrm{ml} / \mathrm{min}$ while simultaneously being superfused with buffer at a flow rate of $12 \mathrm{ml} / \mathrm{min}$. A temperature of $31^{\circ} \mathrm{C}$ was chosen to slow the spontaneous heart rate, and thereby to facilitate pacing. This temperature was also expected to slow conduction, and thus facilitate comparisons of conduction velocity in mice of different genotypes. Spontaneous heart rate in neonatal hearts under these conditions averaged $107 \pm 36$ beats/min before the initiation of paced recordings, and $104 \pm 32$ beats $/ \mathrm{min}$ at the conclusion of paced recordings $(P=0.78)$. A linear electrode array consisting of 16 bipolar pairs (interelectrode distance $200 \mu \mathrm{m}$ ) was placed on the anterior surface of each neonatal or adult heart along the maximal apical-basal dimension. Care was taken to place the electrode array in the same location in each heart in an orientation roughly parallel to the left anterior descending coronary artery. The electrode array traversed the atrioventricular groove such that some electrodes recorded atrial electrical activity. After a 5-min stabilization interval, spontaneous and paced electrical activity was recorded. The time required to complete the electrophysiologic recordings for each heart was $8 \pm 4 \mathrm{~min}$. Paced beats (twice threshold at a basic cycle length of $300 \mathrm{msec}$ ) were initiated with a bipolar electrode at the ventricular apex. Refractory periods were determined by the extrastimulus technique. A drive of $8 \mathrm{~S}_{1}$ beats was delivered at a basic cycle length of $300 \mathrm{~ms}$ followed by a single $S_{2}$ beat that was initially delivered at a coupling interval of $190 \mathrm{~ms}$, and decreasing thereafter by $5 \mathrm{~ms}$ until $\mathrm{S}_{2}$ failed to capture. In some hearts, an atrioventricular conduction time was determined during spontaneous beats, and was defined as the interval between activation of two adjacent electrodes that traversed the atrioventricular groove. This interval was long in relation to the time required to activate two adjacent electrodes on the ventricular surface, and was, therefore, used as a crude measure of conduction through the atrioventricular junction. Electrograms were recorded on a multichannel computerized data acquisition system. Activation times were defined by determining the maximum absolute amplitude of each electrogram (peak criterion) (9), and the average conduction velocity was calculated by linear regression relating interelectrode distance to activation times. The slope of the regression line was the average conduction velocity.

In additional studies, the hearts of three $\mathrm{Cx} 43+/+$ and three $-/+$ mice were fixed in formalin, sliced transversely at $1-\mathrm{mm}$ intervals from apex to base, and embedded in paraffin for histologic analysis of left ventricular structure. Ventricular wall thickness and the orientation of fibers in the ventricular muscle layers at different levels along the apical-basal axis were assessed to determine whether any apparent differences in wall structure or fiber orientation relative to the position of the electrode array could have affected conduction velocity measurements.

Electrocardiography studies. Adult mice were lightly anesthetized with methoxyflurane. Needle electrodes were inserted subcutaneously into each of the four limbs. Simultaneous standard ECG leads I, II, and III were recorded at a frequency response of 0.05-500 $\mathrm{Hz}$ (ECG amplifier model 13-4615-64; Gould Inc., Instruments Divi- sion, Santa Clara, CA). The signal was digitized at 2,000 Hz, and was recorded on a PC. Onset and offsets of $\mathrm{P}, \mathrm{Q}, \mathrm{R}$, and $\mathrm{S}$ waves were calculated by determining the earliest (onset) and latest (offset) times from the three simultaneous leads. From these values, QRS duration and PQ intervals were calculated.

Tissue culture of disaggregated neonatal ventricular myocytes. Neonatal hearts were processed individually by rapid, aseptic removal into ice-cold, filter-sterilized $(0.2 \mu \mathrm{m})$ Hanks' balanced salt solution (HBSS) containing (mM): $137 \mathrm{NaCl}, 5.4 \mathrm{KCl}, 4.2 \mathrm{NaHCO}_{3}, 0.4$ $\mathrm{Na}_{2} \mathrm{HPO}_{4}, 0.44 \mathrm{KH}_{2} \mathrm{PO}_{4}, 5.5$ glucose, at $\mathrm{pH} 7.45$, and $1 \%$ penicillin/ streptomycin. Great vessels and atria were carefully removed under a dissecting microscope. Two longitudinal cuts were made in the remaining ventricles, which were then rinsed in fresh HBSS and transferred to $2 \mathrm{ml}$ of HBSS containing freshly prepared and filter-sterilized $(0.2 \mu \mathrm{m}) 0.1 \%$ trypsin (Type I; Sigma Chemical Co., St. Louis, MO) at $4^{\circ} \mathrm{C}$ for $18 \mathrm{~h}$, followed by incubation for $30 \mathrm{~min}$ in a $37^{\circ} \mathrm{C}$ shaking $(60 \mathrm{~Hz})$ water bath. The tissue was gently triturated using a fire-polished pasteur pipette to disperse individual myocytes. Disaggregated cells were filtered through a $35-\mu \mathrm{m}$ cell strainer, centrifuged at $800 \mathrm{rpm}$ for $1 \mathrm{~min}$, resuspended in $2 \mathrm{ml}$ Dulbecco's Modified Eagle's Medium (DMEM; GIBCO BRL, Gaithersburg, MD) containing $20 \%$ heat-inactivated fetal calf serum and $1 \%$ penicillin-streptomycin, and preplated to selectively remove fibroblasts from the myocyte preparation. After $1.5 \mathrm{~h}$ at $37^{\circ} \mathrm{C}$ in an incubator equilibrated with $5 \%$ $\mathrm{CO}_{2}$, ventricular myocytes from individual hearts were plated at a density of $1 \times 10^{5}$ cells $/ \mathrm{cm}^{2}$ on collagen-coated glass coverslips (12 $\mathrm{mm}$ diameter) placed in a 24-well culture plate. Overall cell yields were approximately $1-3 \times 10^{5}$ cells per heart. The DMEM medium was changed every $24 \mathrm{~h}$.

Cellular electrophysiology. Cells were studied after 3-5 d in culture. Coverslips were transferred to a recording bath ( $0.5 \mathrm{ml}$ volume $)$ outfitted with an $\mathrm{Ag} / \mathrm{AgCl}$ ground and a temperature probe. Cells were perfused $(3 \mathrm{ml} / \mathrm{min})$ at $37^{\circ} \mathrm{C}$ with an extracellular solution containing (mM): $137 \mathrm{NaCl}, 4 \mathrm{KCl}, 1 \mathrm{MgCl}_{2}, 1.8 \mathrm{CaCl}_{2}, 10$ Hepes, and 11 glucose at $\mathrm{pH}$ 7.4. Spontaneously contracting myocytes were currentclamped in the whole-cell configuration using pipettes filled with $(\mathrm{mM}): 20 \mathrm{KCl}, 120 \mathrm{~K}$-aspartate, $2 \mathrm{MgCl}_{2}, 5 \mathrm{Na}_{2}$-ATP, and $10 \mathrm{Hepes}$ at pH 7.05. Transmembrane voltages were amplified with an Axoclamp$2 \mathrm{~A}$ and stored on videotape for offline analysis. A junction potential of $9 \mathrm{mV}$ was corrected before each recording. Recordings were made from individual cells, cell pairs, and small cell groups that contracted spontaneously. Membrane capacitance was measured in voltageclamp mode by delivering a ramp pulse $(\mathrm{dV} / \mathrm{dt}=4 \mathrm{~V} / \mathrm{s})$, and dividing the half-amplitude of the current jump by the rate of the ramp.

Immunoblot analysis. Ventricular homogenates were prepared in PBS. Samples $(50 \mu \mathrm{g})$ were resolved by SDS-polyacrylamide gel electrophoresis, transferred to Immobilon membranes (Millipore Corp., Bedford, MA), and incubated with anti-Cx43 and anti-Cx45 antibodies as previously described (10). Immunoreactivity was detected by chemiluminescence (ECL; Amersham Corp., Arlington Heights, IL) and quantified with densitometric analysis as previously described (10).

Statistical analysis. All values are expressed as mean \pm standard deviation. Two group comparisons were made using the unpaired $t$ test. A $P$ value $<0.05$ was considered significant.

\section{Results}

Ventricular conduction in neonatal mice. Because our original goal was to characterize ventricular conduction in $\mathrm{Cx} 43-/-$ mice (which die shortly after birth), hearts were obtained immediately from newborn animals and placed in cold, oxygenated cardioplegic solution until analysis with the electrode array in a superfusion bath. Attempts to record electrical activity in response to pacing in neonatal $\mathrm{Cx} 43-/-$ hearts $(n=5)$, however, were unsuccessful, even when fetuses were delivered at term (day 20 postcoitum) by cesarean section. Hearts of 
Cx43 - / - animals were maintained under conditions in which $\mathrm{Cx} 43-/+$ and $+/+$ hearts remained viable and electrophysiologically stable for $>3 \mathrm{~h}$. In the time required to excise and prepare for recording the hearts of $\mathrm{Cx} 43-/-$ fetuses delivered by cesarean section or $\mathrm{Cx} 43-/-$ neonates, rhythmic contractions had ceased, and only occasional weak spontaneous beats were noted. Our inability to record reliably either spontaneous or paced electrical activity in $\mathrm{Cx} 43-/-$ hearts suggests that these animals develop profound functional defects upon disruption of the maternal-fetal circulation. Reaume et al. (8) have implicated right ventricular outflow tract obstruction due to a malformation of the conus as the cause of death in $\mathrm{Cx} 43$ $-1-$ mice.

In contrast to $\mathrm{Cx} 43-/-$ neonates, which were readily distinguished from their littermates because they were cyanotic, failed to feed, and were cast aside by their mothers, $\mathrm{Cx} 43-1+$ and $+/+$ neonatal animals were indistinguishable. Accordingly, conduction studies in neonatal $\mathrm{Cx} 43-/+$ and $+/+$ hearts were performed without prior knowledge of the genotypes. Neonatal $\mathrm{Cx} 43-/+$ and $+/+$ hearts could be maintained in cold, oxygenated cardioplegic solution for several hours, and when superfused with oxygenated buffer at $31^{\circ}$, they exhibited stable electrophysiologic function. Results of preliminary studies using $\mathrm{Cx} 43+/+$ neonatal hearts revealed no difference in epicardial conduction velocity measured in superfused hearts immediately after cardiectomy or after incubation in cold cardioplegic solution for $>3 \mathrm{~h}$. Under these superfusion conditions, the spontaneous heart rate was $99 \pm 50$ beats/ min in $\mathrm{Cx} 43-/+$ hearts, and $101 \pm 55$ beats/min in $\mathrm{Cx} 43+/+$ hearts $(P=0.88)$.

Fig. $1, A$ and $B$ are representative electrograms obtained from $\mathrm{Cx} 43+/+$ and $\mathrm{Cx} 43+/-$ neonatal hearts. They demonstrate marked conduction slowing as indicated by the spread of activation times in the $\mathrm{Cx} 43-/+$ heart. Fig. $1 C$ and Table I summarize the results of studies in multiple neonatal hearts from several litters. Longitudinal ventricular conduction of paced beats was $30 \%$ slower in Cx43-/+ $(0.14 \pm 0.04 \mathrm{~m} / \mathrm{s}, n=$ 27) than in $\mathrm{Cx} 43+/+(0.20 \pm 0.07 \mathrm{~m} / \mathrm{s}, n=32, P<0.001)$ neo-
Table I. Electrophysiologic Analysis of Cx43-/+ and + + + Mice

\begin{tabular}{|c|c|c|c|}
\hline & $\begin{array}{l}\text { Conduction } \\
\text { velocity }\end{array}$ & $\begin{array}{l}\text { Refractory } \\
\text { period }\end{array}$ & $\begin{array}{l}\text { Atrioventricular } \\
\text { conduction interval }\end{array}$ \\
\hline & $\mathrm{m} / \mathrm{sec}$ & $\mathrm{m} / \mathrm{sec}$ & $\mathrm{m} / \mathrm{sec}$ \\
\hline \multicolumn{4}{|l|}{ Neonates } \\
\hline $\mathrm{Cx} 43-1+$ & $\begin{array}{c}0.14 \pm 0.04 * \\
(n=27)\end{array}$ & $\begin{array}{l}157 \pm 29 \\
(n=27)\end{array}$ & $\begin{array}{c}90 \pm 24 \\
(n=23)\end{array}$ \\
\hline $\mathrm{Cx} 43+/+$ & $\begin{array}{r}0.20 \pm 0.07 \\
(n=30)\end{array}$ & $\begin{array}{l}146 \pm 19 \\
(n=29)\end{array}$ & $\begin{array}{l}104 \pm 43 \\
(n=28)\end{array}$ \\
\hline \multicolumn{4}{|l|}{ Adults } \\
\hline $\mathrm{Cx} 43-1+$ & $\begin{array}{c}0.18 \pm 0.03 * \\
\quad(n=5)\end{array}$ & $\begin{array}{l}110 \pm 17 \\
(n=5)\end{array}$ & - \\
\hline $\mathrm{Cx} 43+/+$ & $\begin{array}{c}0.32 \pm 0.07 \\
(n=7)\end{array}$ & $\begin{array}{l}117 \pm 40 \\
(n=5)\end{array}$ & - \\
\hline
\end{tabular}

Values are means $\pm \mathrm{SD} ; * P<0.001$ vs. $\mathrm{Cx} 43+/+$ value.

natal hearts. No significant differences were observed in refractory period or in atrioventricular conduction times.

Ventricular conduction and surface ECG in adult mice. To determine whether the slowed ventricular conduction observed in $\mathrm{Cx} 43-/+$ neonates persisted in adult mice, we analyzed ventricular conduction in animals 6-9 mo of age. The larger size of the adult heart allowed us to cannulate the aorta, and to perfuse the hearts with oxygenated buffer. The perfused hearts were submerged in the tissue bath, and were simultaneously superfused with buffer at $31^{\circ} \mathrm{C}$. Under these conditions, spontaneous heart rates were $164 \pm 56$ beats $/ \mathrm{min}$ for Cx43 -/+ hearts, and $198 \pm 28$ beats/min for $\mathrm{Cx} 43+/+$ hearts $(P=0.26)$. As shown in Fig. 2, epicardial conduction was $44 \%$ slower in $\mathrm{Cx} 43-/+$ ventricles $(0.18 \pm 0.03 \mathrm{~m} / \mathrm{s}, n=5)$ than in $\mathrm{Cx} 43+/+$ ventricles $(0.32 \pm 0.07 \mathrm{~m} / \mathrm{s}, n=7, P<0.001)$.

No differences were observed in refractory periods in adult $\mathrm{Cx} 43-/+$ and $+/+$ mice. In both neonatal and adult animals,

\section{A Neonatal Cx43+/+ B Neonatal Cx43 -/+}

12

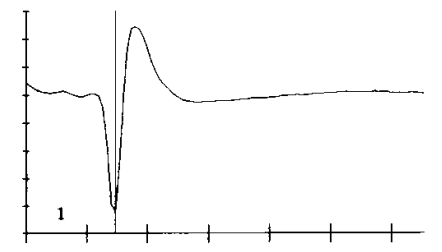

14

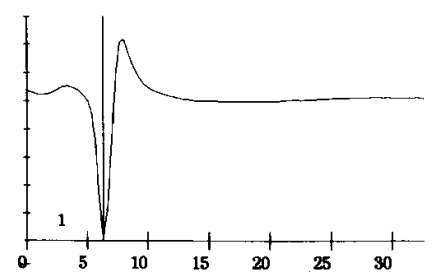

12

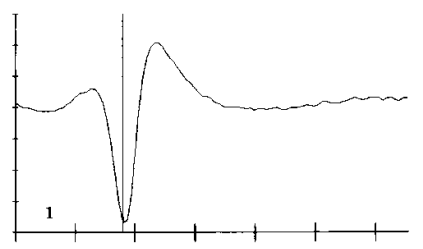

14

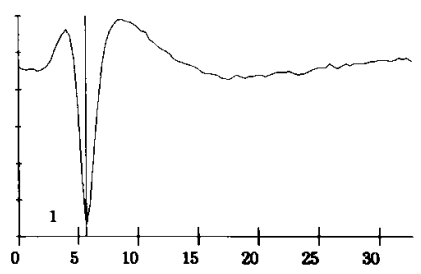

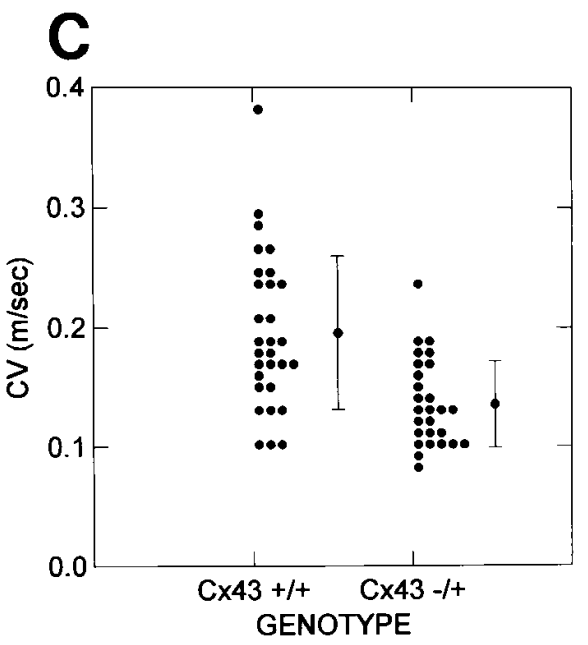

Figure 1. ( $A$ and $B)$ Representative electrograms recorded at two electrode sites from $\mathrm{Cx} 43+/+$ and $-/+$ neonatal hearts. Vertical lines indicate the maximum amplitude of each electrogram. The distance between the vertical lines indicates the time (in ms) required to activate tissue between the two electrode sites. Conduction velocities were calculated on the basis of the points of maximal amplitude. $(C$ ) Ventricular conduction velocity in neonatal hearts. 

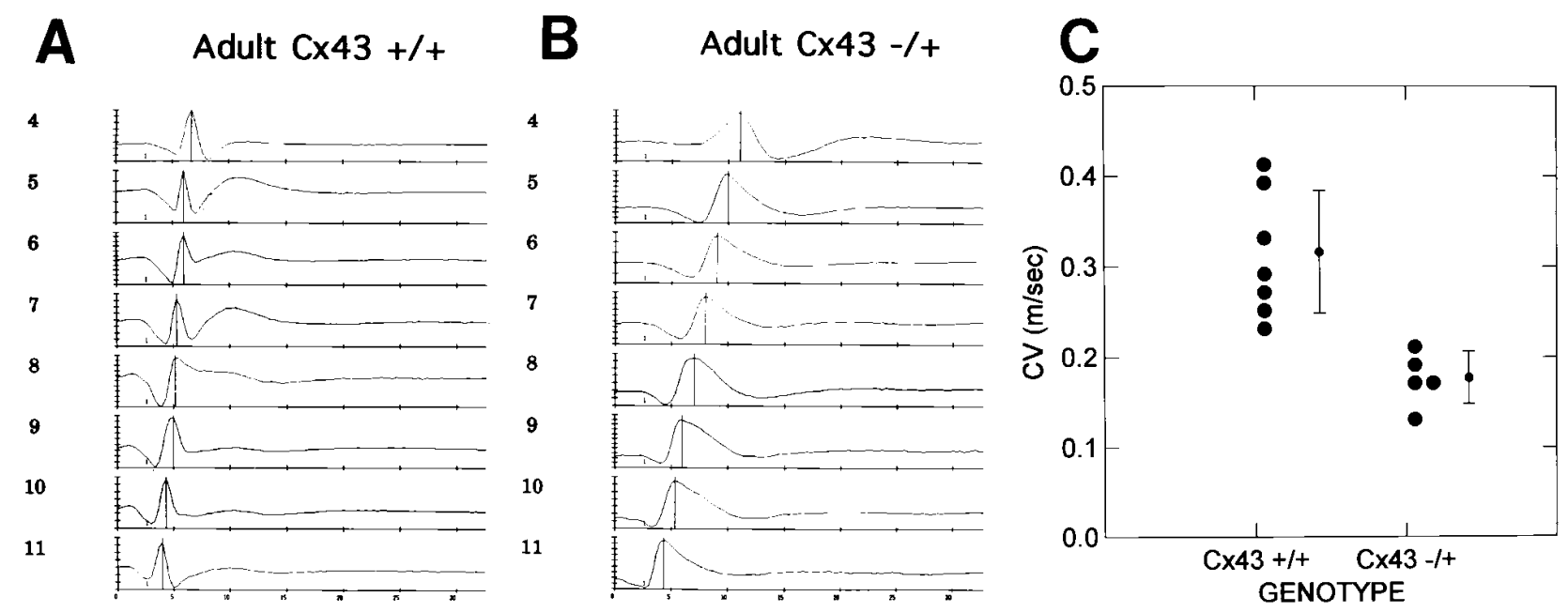

Figure 2. $(A$ and $B)$ Sequential electrograms from the ventricular epicardial surface of adult $\mathrm{Cx} 43+/+$ and $-/+$ hearts. Vertical lines indicate the maximum amplitude of each electrogram. Conduction velocities were calculated on the basis of the points of maximal amplitude. Ventricular conduction velocity was $0.34 \mathrm{~m} / \mathrm{s}$ in the $\mathrm{Cx} 43+/+$ heart, and $0.17 \mathrm{~m} / \mathrm{s}$ in the $\mathrm{Cx} 43-/+$ heart. $(C)$ Ventricular conduction velocity in adult hearts.

the refractory periods were relatively long compared to the relatively short action potential durations recorded from individual isolated neonatal myocytes (see below). This long refractory period may have been due to the low temperature $\left(31^{\circ} \mathrm{C}\right)$ of the bath, or may have been related to recording refractory periods from whole hearts in a tissue bath. Nevertheless, because $\mathrm{Cx} 43-/+$ and $+/+$ hearts were analyzed under identical conditions, it is unlikely that alterations in refractory period in $\mathrm{Cx} 43-/+$ hearts influenced conduction velocity measurements. We also observed no correlation between electrogram amplitude and $\mathrm{Cx} 43$ genotype.

The hearts of adult $\mathrm{Cx} 43-/+$ and $+/+$ mice were studied histologically to compare the structure of the left ventricle. No difference was observed in anterior or posterior free wall thickness (measured in each heart in a transverse slice located approximately midway between the ventricular apex and the atrioventricular groove) in $\mathrm{Cx} 43-/+$ hearts $(1.1 \pm 0.1 \mathrm{~mm}$, 6 measurements in 3 hearts) and $\mathrm{Cx} 43+/+$ hearts $(1.1 \pm 0.1 \mathrm{~mm}$, 6 measurements in 3 hearts). Fig. 3 shows representative transmural sections of the anterior left ventricular free wall in a transverse slice roughly midway between the apex and atrioventricular groove. The plane of section is approximately perpendicular to the orientation of the electrode array. The structure of the wall is similar to that observed in mammalian hearts, and consists of three relatively distinct muscle layers having different fiber orientations. The epicardial layer is cut obliquely in the plane of section shown in Fig. 3. The midmyocardial layer is cut in longitudinal section, and the inner (subendocardial) layer is sectioned obliquely. No obvious differences in fiber orientation or curvature in the apical-basal

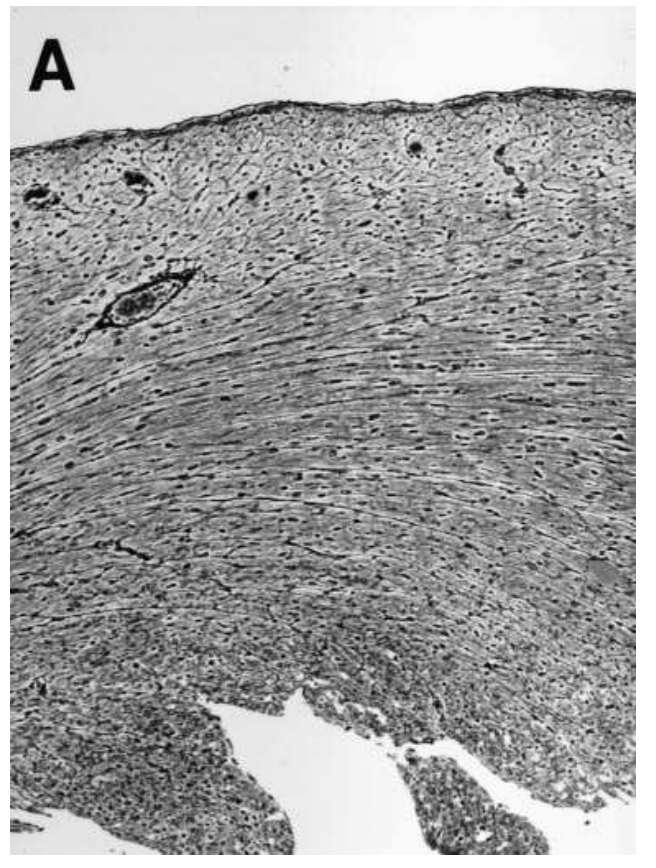

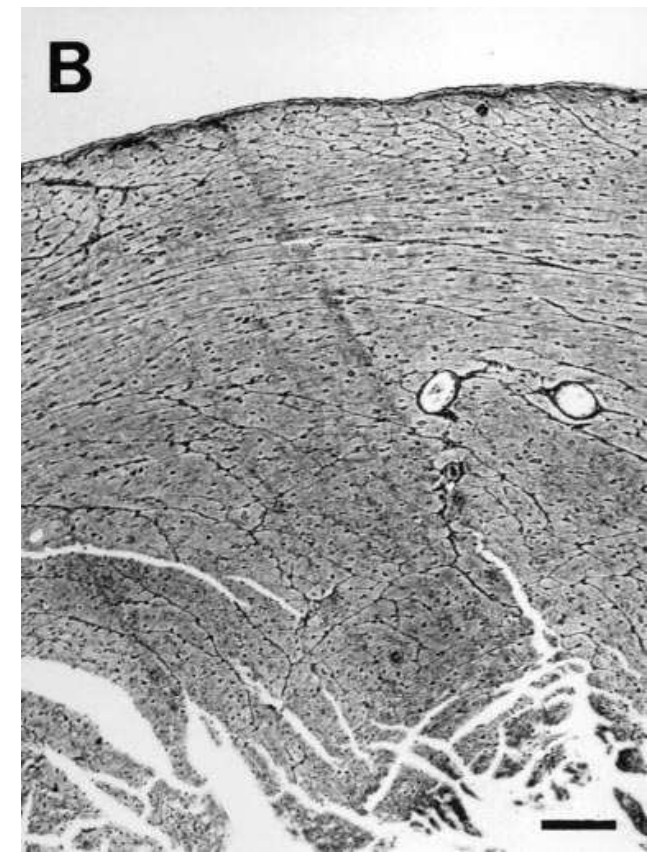

Figure 3. Representative transmural histologic sections of the anterior left ventricular free wall of $\mathrm{Cx} 43-1+(A)$ and $+/+$ hearts $(B)$. The tissue has been stained with a reticulin stain to highlight the interstitium and outline individual cells. In conduction studies, the linear electrode array was oriented approximately perpendicular to the epicardial (upper) surface, which has been cut in a transverse plane of section in these images. No apparent differences were observed in fiber orientation or the histologic structure of the ventricular walls of $\mathrm{Cx} 43-1+$ and $+/+$ hearts. Bar $=0.1 \mathrm{~mm}$. 


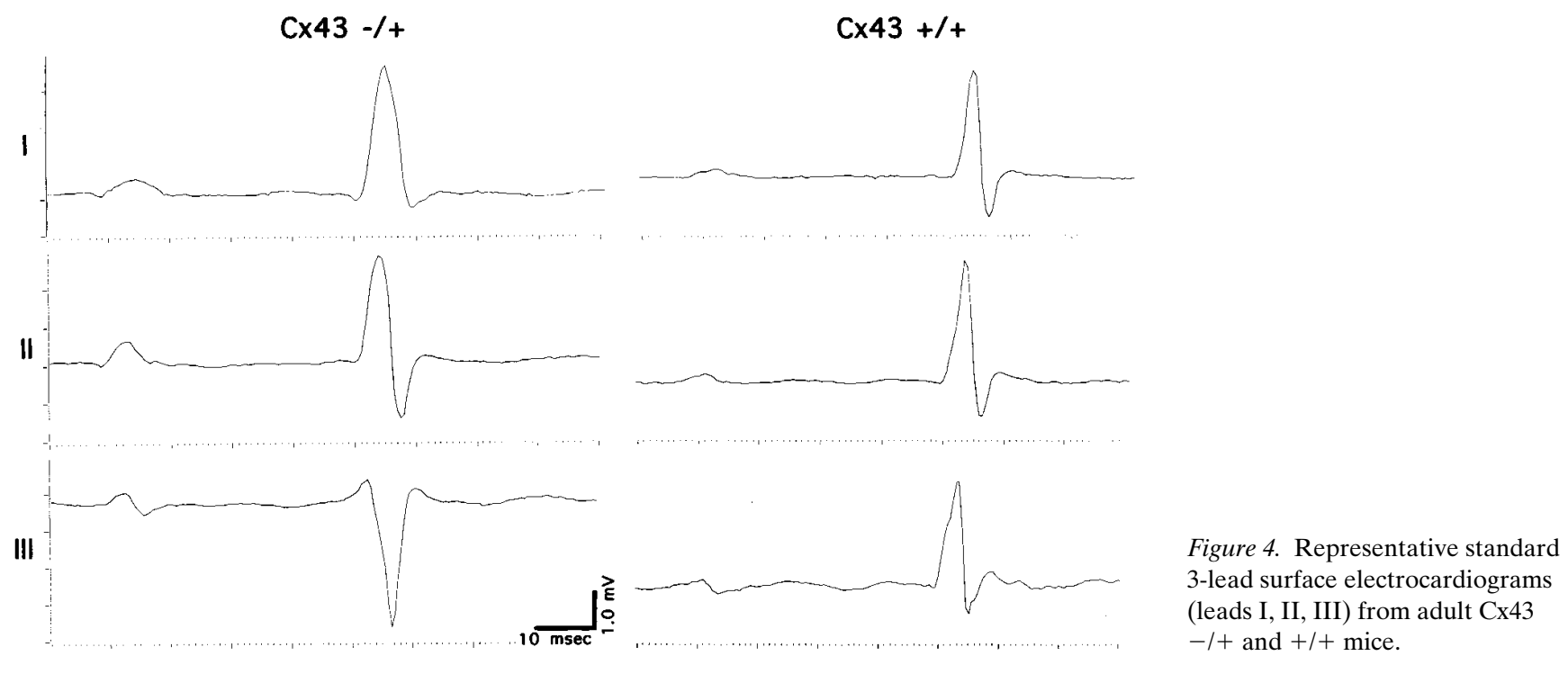

dimension were apparent in subserial transverse sections of three $\mathrm{Cx} 43-/+$ and three $\mathrm{Cx} 43+/+$ hearts.

Simultaneous three-lead ECGs were performed on lightly anesthetized adult $\mathrm{Cx} 43-/+(n=13)$ and $\mathrm{Cx} 43+/+(n=12)$ animals. Representative tracings are shown in Fig. 4. Heart rates were much more rapid under these conditions than in isolated hearts perfused and superfused with buffer at $31^{\circ} \mathrm{C}$. No differences in heart rate were observed between $\mathrm{Cx} 43-1+$ animals $(457 \pm 57$ beats $/ \mathrm{min})$ and $\mathrm{Cx} 43+/+$ animals $(484 \pm 76$ beats $/ \mathrm{min}, P=0.31)$, nor were differences in PQ interval observed ( $44 \pm 5 \mathrm{~ms}, \mathrm{Cx} 43-/+; 44 \pm 8 \mathrm{~ms}, \mathrm{Cx} 43+/+; P=0.76)$. The QRS interval, however, was significantly longer in $\mathrm{Cx} 43$ $-/+(13.4 \pm 1.8 \mathrm{~ms})$ than in $\mathrm{Cx} 43+/+$ animals $(11.5 \pm 1.4 \mathrm{~ms}$, $P<0.01)$. Taken together, the results of the conduction studies and ECG measurements indicate that ventricular conduction is slowed in both $\mathrm{Cx} 43-1+$ neonates and adults.

Cellular electrophysiology. Studies were performed to determine whether the observed conduction defect resulted from changes in action potential parameters. Whole-cell recordings were made in primary cultures of neonatal $\mathrm{Cx} 43-1+(n=6)$ and $+/+(n=11)$ ventricular myocytes isolated from individual ventricles. All recordings were obtained without prior knowledge of the genotype. Immediately upon attaining the whole-cell configuration, the intrinsic rate of the cell being studied usually slowed to a minimum value, at which time a maximum diastolic potential (MDP) that most closely represented a resting potential was recorded (Table II, MDP ${ }_{1}$ ). Thereafter, the cells settled into a more rapid intrinsic rate (100-400 beats/min) and exhibited a more depolarized membrane potential (Table II, $\mathrm{MDP}_{2}$ ). As shown in Fig. 5 and Table II, there were no differences in action potential morphology, or any action potential parameter, including maximum diastolic potential, maximum upstroke velocity of phase 0 , or action potential durations. Maximum upstroke velocities were rapid (180-200 V/s).

Membrane capacitance was measured in the voltage-clamp mode in isolated neonatal ventricular myocytes. No significant difference was observed between $\mathrm{Cx} 43-/+$ myocytes $(36.4 \pm 6.0$ $\mathrm{pF}, n=9)$ and $\mathrm{Cx} 43+/+$ myocytes $(34.0 \pm 4.9 \mathrm{pF}, n=11)$. These observations indicate that isolated neonatal $\mathrm{Cx} 43-/+$ and $+/+$ ventricular myocytes are of equivalent size.
Immunoblot analysis. Total protein homogenates from six individual adult $\mathrm{Cx} 43-/+$ and six $\mathrm{Cx} 43+/+$ ventricles were analyzed by immunoblotting (Fig. 6). Densitometric analysis revealed that $\mathrm{Cx} 43$ protein content in $-1+$ ventricle was $0.50 \pm 0.06$ of the $\mathrm{Cx} 43$ content in $+/+$ ventricles $(P<0.001)$. No significant difference was observed in $\mathrm{Cx} 45$ content of $\mathrm{Cx} 43-1+(0.82 \pm 0.35$ of wild-type value, $P=0.45)$ and $+/+$ ventricles.

\section{Discussion}

The results of this study indicate that the velocity of ventricular epicardial conduction is slowed in neonatal and adult mice that harbor null alleles for $\mathrm{Cx} 43$, the principal cardiac connexin. Conduction velocity is determined by many interdependent active and passive properties of cardiac myocytes. Wholecell recordings revealed no differences in any action potential parameter in ventricular myocytes isolated from neonatal $\mathrm{Cx} 43-/+$ and $+/+$ mice, suggesting that the observed conduction slowing was not due to changes in active membrane prop-

Table II. Action Potential Characteristics of Cultured Neonatal Ventricular Myocytes

\begin{tabular}{lcc}
\hline & $\mathrm{Cx} 43+/+$ & $\mathrm{Cx} 43-1+$ \\
\hline & $n=11$ & $n=6$ \\
Upon attaining whole-cell configuration & & \\
$\quad$ MDP $_{1}(\mathrm{mV})$ & $-78 \pm 6$ & $-78 \pm 6$ \\
During spontaneous activity & & \\
MDP $_{2}(\mathrm{mV})$ & $-67 \pm 7$ & $-70 \pm 5$ \\
Amplitude $(\mathrm{mV})$ & $103 \pm 11$ & $108 \pm 10$ \\
Overshoot $(\mathrm{mV})$ & $38 \pm 8$ & $41 \pm 6$ \\
Action potential duration $(\mathrm{msec})$ & & \\
50\% Repolarization & $25 \pm 7$ & $25 \pm 15$ \\
$70 \%$ Repolarization & $34 \pm 9$ & $34 \pm 18$ \\
95\% Repolarization & $59 \pm 12$ & $62 \pm 21$ \\
Maximum rate of rise of phase 0 (V/sec) & $184 \pm 44$ & $192 \pm 38$ \\
& & \\
& &
\end{tabular}

Values are means \pm SD; MDP, maximum diastolic potential. 

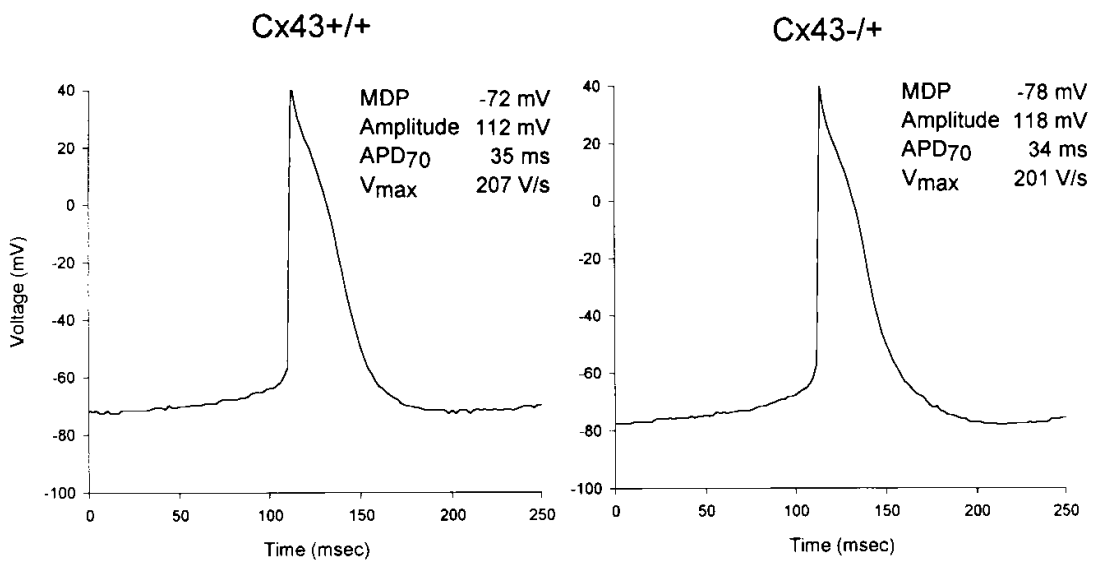

Figure 5. Representative spontaneous action potentials from isolated $\mathrm{Cx} 43+/+$ and $-/+$ neonatal ventricular myocytes. MDP, maximum diastolic potential; $\mathrm{APD}_{70}$, action potential duration at $70 \%$ of repolarization; $\mathrm{V}_{\max }$, maximum rate of rise of phase 0 of the action potential. erties. The amount of $\mathrm{Cx} 43 \mathrm{mRNA}$ and protein in ventricular myocardium was reduced by $\sim 50 \%$ in $\mathrm{Cx} 43-/+$ mice, a value consistent with targeted deletion of a single allele. Thus, our results suggest that a $50 \%$ reduction in the amount of a major cardiac gap junction protein produces a nearly comparable reduction in ventricular conduction velocity.

Ventricular myocytes express both $\mathrm{Cx} 43$ and $\mathrm{Cx} 45$ which have been found to colocalize in gap junctions $(3,11)$. The relative functional roles of these two proteins in ventricular conduction are unknown. Our results indicate that diminished expression of $\mathrm{Cx} 43$ in $\mathrm{Cx} 43-1+$ ventricles does not lead to compensatory upregulation of expression of $\mathrm{Cx} 45$. This finding is consistent with the original report by Reaume et al. (8) who observed no differences by reverse transcription PCR in either Cx45 or Cx40 mRNA content in hearts of 16.5-d-old Cx43-/-, $-/+$, and $+/+$ embryos. Cx40 expression has not been detected in ventricular myocytes in the mouse (12) or in other mammalian hearts, including man $(4,5,10,13-15)$. Thus, the marked slowing of ventricular conduction in $\mathrm{Cx} 43-/+$ mice suggests that $\mathrm{Cx} 43$ is the principal conductor of intercellular charge in the ventricle, whereas $\mathrm{Cx} 45$ may not play a dominant role in this function.

No differences were observed in spontaneous heart rates between $\mathrm{Cx} 43-/+$ and $+/+$ mice either during isolated heart studies in vitro or by electrocardiography. Furthermore, there were no differences in atrioventricular conduction times in isolated neonatal $\mathrm{Cx} 43-/+$ and $+/+$ hearts, or in PQ intervals in adult ECG studies. These observations suggest that deletion of a single $\mathrm{Cx} 43$ allele has no significant effect on sinus node or atrioventricular node function. This conclusion is consistent with previous reports $(7,16,17)$ that $\mathrm{Cx} 43$ may not be expressed at all or as abundantly as other connexins in the nodes

\section{$-/+\quad-/+-/++/++/++/+$}

\section{Cx43}

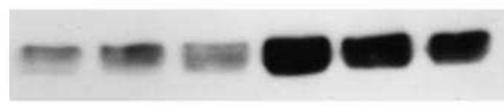

\section{Cx45}

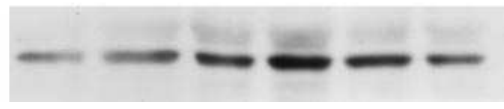

Figure 6. Representative immunoblots showing $\mathrm{Cx} 43$ and $\mathrm{Cx} 45$ protein content in ventricular tissues of $\mathrm{Cx} 43-/+$ and $+/+$ hearts. of the cardiac conduction system. $\mathrm{Cx} 40$ is expressed abundantly in the specialized conduction system $(5,12,13,18)$. Thus, potential alterations in Cx40 expression in the Purkinje system could conceivably contribute to prolongation of the QRS duration seen in Cx43-/+ mice. The absence of apparent differences between $\mathrm{Cx} 43-/+$ and $+/+$ mice in sinus or atrioventricular node function, however, combined with the lack of evidence of changes in expression of $\mathrm{Cx} 40$ or $\mathrm{Cx} 45$ in hearts of $\mathrm{Cx} 43-/-$ and $-/+$ mice (8) makes it unlikely that changes in the specialized conduction system account for differences in ventricular epicardial conduction or QRS duration in $\mathrm{Cx} 43-/+$ and $+/+$ mice. Additional studies involving new animal models in which expression of specific connexins is manipulated genetically will undoubtedly shed light on the functional roles of multiple connexins expressed within individual cardiac myocytes and specific combinations of connexins expressed in functionally distinct conductive tissues.

Because conduction velocities were measured on the epicardial surface after initiating paced beats on the surface, conduction pathways were not defined. It is possible that targeted deletion of a $\mathrm{Cx} 43$ allele could indirectly lead to changes in cell-packing geometry or remodeling of conduction pathways that could affect conduction velocity. Histologic analysis of left ventricular structure, however, revealed no apparent differences in wall thickness or the orientation or fiber curvature in the three muscle layers of the ventricle. Thus, although the electrode array may not have been oriented truly longitudinal to fiber direction throughout its full length, it seems unlikely that differences in ventricular wall structure can account for the slow conduction velocities in neonatal and adult $\mathrm{Cx} 43-/+$ mice. Membrane capacitance measurements in isolated $\mathrm{Cx} 43$ $-/+$ and $+/+$ neonatal ventricular myocytes indicated no difference in cell size, providing further evidence that structural differences were not responsible for conduction slowing in $\mathrm{Cx} 43-/+$ mice. It will be necessary in future studies, however, to characterize the number, size, and three-dimensional distribution of gap junctions to determine whether targeted deletion of a single $\mathrm{Cx} 43$ allele affects the spatial distribution of intercellular connections in ventricular myocardium. It will also be necessary to characterize independently junctional and cytoplasmic resistances to current flow in $\mathrm{Cx} 43-1+$ and $+/+$ myocytes to elucidate the molecular and cellular basis for the slow ventricular conduction caused by the $\mathrm{Cx} 43-/+$ genotype.

Although both neonatal and adult $\mathrm{Cx} 43-/+$ hearts exhib- 
ited a ventricular conduction defect when compared to agematched wild-type hearts, ventricular conduction in neonatal ventricles was considerably slower than in adult ventricles. Results of whole-cell recordings in neonatal myocytes demonstrated rapid upstroke velocities of phase 0 of the action potential, consistent with the conclusion that depolarization was mediated primarily by the fast inward sodium current, $\mathrm{I}_{\mathrm{Na}}$. Because neonatal hearts were only superfused rather then being perfused and superfused, slower conduction in neonatal than in adult ventricles could be attributable to this technical aspect. Another possible explanation for the slower conduction in neonatal as opposed to adult mouse ventricles, is the smaller size of neonatal myocytes, which would cause wavefronts to traverse a greater number of intercellular junctions per unit distance than would be encountered in adult myocardium. Despite the slower absolute values of conduction velocity in neonatal compared with adult hearts, our results in age-matched (littermate) controls clearly indicate that ventricular epicardial conduction is significantly slower in $\mathrm{Cx} 43-/+$ hearts than in wild-type hearts.

Alterations in conduction are critical in the pathogenesis of sudden cardiac death due to reentrant ventricular arrhythmias (19). Activation mapping studies have localized sites of slow conduction and conduction block, critical in the initiation and maintenance of reentrant circuits to regions bordering healed ventricular infarcts (20), or tissue strands surviving within the infarct (21). The distribution of intercellular junctions in these border zone regions is highly deranged $(21,22)$, implicating alterations in gap junctions in the pathogenesis of conduction abnormalities leading to the establishment of anatomic substrates of lethal arrhythmias. Although the extent of intercellular coupling of myocytes at gap junctions is a major determinant of conduction, other factors, including those affecting membrane depolarization and repolarization, undoubtedly play critical roles in arrhythmogenesis. Previously, it has not been possible to characterize the role of intercellular coupling per se on conduction independent of these other factors because experimental interventions designed to alter coupling also affect other determinants of conduction. Because there are no known drugs that selectively alter junctional coupling, previous studies have relied on agents such as heptanol (23-25) or oubain (26) to uncouple cells. These compounds, however, are not specific in their actions. For example, long-chain alcohols have been shown to affect $\mathrm{Na}^{+}$currents $(27,28)$. Furthermore, potential differential effects of long-chain alcohols on channels made by different connexins are unknown. In contrast, the $\mathrm{Cx} 43-1+$ mouse is the first genetic system of which we are aware, in which abnormal conduction arises primarily, if not exclusively, from deficient expression of a single gap junction channel protein. Accordingly, this model has the potential to provide definitive insights into the roles of altered coupling in the pathogenesis of conduction abnormalities critical in the initiation and maintenance of reentrant arrhythmias.

\section{Acknowledgments}

We gratefully acknowledge Dr. Janet Rossant who provided tissue samples from $\mathrm{Cx} 43-/-,-/+$, and $+/+$ animals during the initial phase of the study, and Drs. Subhash Juneja and Gerald Kidder, who provided PCR primers and technical assistance. We also thank Karen Green, Evelyn Kanter, Eileen Westphale, and Dr. Michael Beardslee for technical assistance; Dr. Yoram Rudy and Dr. André Kléber for helpful scientific discussions, and Susan Johnson for secretarial assistance.

Work in the authors' laboratories was supported by National Institutes of Health Grants HL45466 and HL50598. Dr. Guerrero was supported by a National Research Service Award (HL 09366) from the National Heart, Lung, and Blood Institute. Dr. Davis was supported by the B.J. Amos Award from the Westmead Medical Association. Dr. Beyer was supported by an Established Investigator Award from the American Heart Association.

\section{References}

1. Pressler, M.L., P.N. Münster, and X. Huang. 1995. Gap junction distribution in the heart: functional relevance. In Cardiac Electrophysiology-From Cell to Bedside. 2nd ed. D. Zipes and J. Jalife, editors. W.B. Saunders Co., Philadelphia. 144-151.

2. Spach, M.S., and J.F. Heidlage. 1995. The stochastic nature of cardiac propagation at a microscopic level: electrical description of myocardial architecture and its application to conduction. Circ. Res. 76:366-380.

3. Kanter, H.L., J.E. Saffitz, and E.C. Beyer. 1992. Cardiac myocytes express multiple gap junction proteins. Circ. Res. 70:438-444.

4. Saffitz, J.E., H.L. Kanter, K.G. Green, T.K. Tolley, and E.C. Beyer. 1994. Tissue-specific determinants of anisotropic conduction velocity in canine atrial and ventricular myocardium. Circ. Res. 74:1065-1070.

5. Davis, L.M., H.L. Kanter, E.C. Beyer, and J.E. Saffitz. 1994. Distinct gap junction protein phenotypes in cardiac tissues with disparate conduction properties. J. Am. Coll. Cardiol. 24:1124-1132.

6. Beyer, E.C., D.A. Goodenough, and D.L. Paul. 1990. Connexin family of gap junction proteins. J. Membr. Biol. 116:187-194.

7. Veenstra, R.D. 1996. Size and selectivity of gap junction channels formed from different connexins. J. Bioenerg. Biomembr. 28:317-337.

8. Reaume, A.G., P.A. de Sousa, S. Kulkarni, B.L. Langille, D. Zhu, T.C. Davies, S.C. Juneja, G.M. Kidder, and J. Rossant. 1995. Cardiac malformation in neonatal mice lacking connexin43. Science (Wash. DC). 267:1831-1834.

9. Biermann, M., M. Shenasa, M. Borggrefe, G. Hendricks, W. Haverkamp, and G. Breithardt. 1993. The interpretation of cardiac electrograms. In Cardiac Mapping. M. Shenasa, M. Borggrefe, and G. Breithardt, editors. Futura Publishing Company, Inc., Mt. Kisco. 11-34.

10. Darrow, B.J., V.G. Fast, A.G. Kléber, E.C. Beyer, and J.E. Saffitz. 1996. Functional and structural assessment of intercellular communication: increased conduction velocity and enhanced connexin expression in dibutyryl cAMPtreated cultured cardiac myocytes. Circ. Res. 79:174-183.

11. Kanter, H.L., E.C. Beyer, K.G. Green, and J.E. Saffitz. 1993. Multiple connexins colocalize in canine cardiac myocyte gap junctions. Circ. Res. 74:344350 .

12. Traub, O., R. Eckert, H. Lichtenberg-Frate, C. Elfgang, B. Bastide, K.H. Scheidtmann, D.F. Hulser, and K. Willecke. 1994. Immunochemical and electrophysiological characterization of murine connexin 40 and -43 in mouse tissue and transfected human cells. Eur. J. Cell Biol. 64:101-112.

13. Bastide, B., L. Neyses, D. Ganten, M. Paul, F. Willecke, and O. Traub. 1993. Gap junction protein connexin 40 is preferentially expressed in vascular endothelium and conductive bundles of rat myocardium and is increased under hypertensive conditions. Circ. Res. 73:1138-1149.

14. Gros, D., T. Jarry-Guichard, I. Ten Velde, A. de Maziere, J.A. van Kempen, J. Davoust, J.P. Briand, A.F.M. Moorman, and J.H. Jongsma. 1994. Restricted distribution of connexin40, a gap junctional protein, in mammalian heart. Circ. Res. 74:839-851.

15. Gourdie, R.G., N.H. Severs, C.R. Green, S. Rothery, P. Germroth, and R.P. Thompson. 1993. The spatial distribution and relative abundance of gapjunctional connexin 40 and connexin 43 correlate to functional properties of components of the cardiac atrioventricular conduction system. J. Cell Sci. 105: 985-991.

16. Oosthoek, P.W., S. Viragh, A.E.M. Mayen, M.J.A. van Kempen, W.H. Lamers, and A.F.M. Moorman. 1993. Immunohistochemical delineation of the conduction system. I. The sinoatrial node. Circ. Res. 73:473-481.

17. Oosthoek, P.W., S. Viragh, W.H. Lamers, and A.F.M. Moorman. 1993. Immunohistochemical delineation of the conduction system. II. The atrioventricular node and the Purkinje fibers. Circ. Res. 73:482-491.

18. Kanter, H.L., J.G. Laing, S.L. Beau, E.C. Beyer, and J.E. Saffitz. 1993. Distinct patterns of connexin expression in canine Purkinje fibers and ventricular muscle. Circ. Res. 72:1124-1131.

19. Janse, M.J., and A.L. Wit. 1989. Electrophysiological mechanisms of ventricular arrhythmias resulting from myocardial ischemia and infarction. Physiol. Rev. 69:1049-1169.

20. Dillon, S.M., M.A. Allessie, P.C. Ursell, and A.L. Wit. 1988. Influences of anisotropic tissue structure and reentrant circuits in the epicardial border zone of subacute canine infarcts. Circ. Res. 63:182-206.

21. DeBakker, M.J.T., F.J.L. van Capelle, M.J. Janse, S. Tasseron, J.T. Vermeulen, N. de Jonge, and J.R. Lahpor. 1993. Slow conduction in the infarcted 
human heart. "Zigzag" course of activation. Circulation. 88:915-926.

22. Luke, R.A., and J.E. Saffitz. 1991. Remodeling of ventricular conduction pathways in healed canine infarct border zones. J. Clin. Invest. 87:15941602.

23. Delmar, M., D.C. Michaels, T. Johnson, and J. Jalife. 1987. Effects of increasing intracellular resistance on transverse and longitudinal propagation in sheep epicardial muscle. Circ. Res. 60:780-785.

24. Brugada, J., L.L. Mont, L. Boersma, C. Kirchhof, and M. Allessie. 1991. Differential effects of heptanol, potassium and tetrodotoxin on reentrant ventricular tachycardia around a fixed obstacle in anisotropic myocardium. Circulation. 84:1307-1318.
25. Callans, D.J., E.N. Moore, and J.F. Spear. 1996. Effect of coronary perfusion of heptanol on conduction and ventricular arrhythmias in infarcted canine myocardium. J. Cardiovasc. Electrophysiol. 7:1159-1171.

26. Spach, M.S., M. Kootsey, and J.D. Sloan. 1982. Active modulation of electrical coupling between cardiac cells of the dog. A mechanism for transient and steady state variations in conduction velocity. Circ. Res. 51:347-362.

27. Oxford, G.S., and R.P. Swenson. 1979. n-Alkanols potentiate sodium channel inactivation in squid giant axons. Biophys. J. 26:585-590.

28. Nelson, W.L., and J.C. Makielski. 1991. Block of sodium current by heptanol in voltage-clamped canine cardiac Purkinje cells. Circ. Res. 68:977-983. 